\title{
Visiones de Marsella, de Moholy a Muntadas
}

\author{
JAVIER PÉREZ SEGURA
}

Profesor Titular de Historia del Arte. Departamento de Historia del Arte III (Contemporáneo). Universidad Complutense de Madrid

javierpsegura@yahoo.es

\section{Resumen}

Marsella siempre ha asumido un papel protagonista en las reflexiones culturales de Francia y del resto de Europa. Este ensayo analiza dos miradas de sendos artistas sobre la ciudad: la del húngaro Lázslo Moholy-Nagy (con su film Impressions du Vieux Port de Marseille, 1928) y la del videoartista catalán Antoni Muntadas (Marseille: mythes et stéréotypes. Regard des regards, 1995).

Palabras clave: Marsella; imagen de la ciudad; cine; videoarte; Lázslo Moholy-Nagy; Antoni Muntadas.

\section{Visions of Marseille, from Moholy to Muntadas}

\begin{abstract}
The French city of Marseille has always developed a leading role in France's and rest of Europe's cultural considerations. This essay analyses two proposals from two different artists: the Hungarian Lázslo Moholy-Nagy (concerning his movie Impressions du Vieux Port de Marseille, 1928) and the Catalan videoartist Antoni Muntadas (Marseille: mythes et stéréotypes. Regard des regards, 1995).
\end{abstract}

Keywords: Marseille; image of the city; cinema; videoart; Lázslo Moholy-Nagy; Antoni Muntadas

Sumario: 1.- Visiones de Marsella, de Moholy a Muntadas. 2.- A vueltas con la metrópoli y con las ciudades que no lo son. 3.- La caleidoscópica mirada de lo posmoderno: Muntadas. 4. Referencias bibliográficas. 


\section{Visiones de Marsella, de Moholy a Muntadas ${ }^{1}$}

Una de las películas -adscritas al género conocido como "sinfonías urbanas"- más difíciles de encuadrar en el periodo de entreguerras es el que dirigió en 1929 Lazslo Moholy-Nagy: Impresiones del Viejo Puerto de Marsella. A primera vista parece una rareza incómoda dentro de una producción como la del húngaro, centrada casi enteramente en los experimentos de la abstracción, pero quizás no lo sea tanto, al menos ésta es mi hipótesis.

Como introducción, debemos decir que entre 1925 y 1928 escribe su texto teórico La Nueva Visión, que sería una de las monografías de la editorial de la Bauhaus, donde él trabajaba como profesor. Poco después -junto a Walter Gropius y Herbert Bayer- abandona la institución para no someterse a las crecientes presiones políticas que culminarían, en 1933, con el cierre de la institución, cuando Mies van der Rohe acababa de hacerse con su dirección. Volviendo al texto de Moholy, en La Nueva Visión denuncia el sistema de producción industrial y apuesta, entre otros aspectos, por una vuelta al trabajo individualizado que estaría centrado en la recuperación de las cualidades intrínsecas de los materiales y, en especial, de sus valores táctiles: [...] Los valores táctiles, ordenados expresamente, pueden originar un nuevo tipo de expresión [...] tienen el poder de liberar una nueva sensación de vida ${ }^{2}$.

Esa nueva sensación de vida es la que va a perseguir durante toda esa década. El cine experimental, pero en el que a menudo caben matices documentales, será uno de sus medios más valorados durante esa década de los años veinte. Con la media decena de películas que realizó en el periodo de entreguerras ayudó mucho a contestar preguntas centrales sobre cómo poder traducir la imagen de la ciudad moderna o, incluso, cómo crearlo de forma consciente.

Anticipando los contenidos que vamos a tratar, Moholy Nagy demostró a través de sus películas que la ciudad moderna no sólo es una tipología -el rascacielos- sino, principalmente, un ritmo de vida vertiginoso. También, que

\footnotetext{
${ }^{1}$ Este texto se inscribe en los trabajos del Grupo Arte, Arquitectura y Comunicación en la Ciudad Contemporánea. Grupo de Investigación Consolidado, UCM. Campus de Excelencia Internacional Moncloa.

${ }^{2}$ He consultado la edición de Buenos Aires, Infinito, 1963, pág. 37.
} 
existían muchas maneras de narrar ese hecho urbano, dando primacía a lo experimental y huyendo de las habituales alabanzas fáciles hacia la máquina como genio creador de un nuevo mundo, de una nueva ciudad.

El primero de sus filmes se titula Dinámica de una gran ciudad (1922). De una fecha muy temprana, esto no hace sino que lamentemos que sólo quedara como proyecto sobre el papel, como guión escrito junto a su amigo Carl Koch. En los fotocollages que se conservan de ese proyecto vemos líneas oblicuas, diagonales, fotografías de fábricas pero también retratos, animales, incluso algún collage de genealogía dadaísta, muy en la línea de Raoul Hausmann o Hannah Höch, por citar sólo a dos de los más conocidos en ese campo.

Moholy-Nagy era consciente de la importancia que podría tener esa película y por ello cuenta con detenimiento las motivaciones de ese film, finalmente no nato:

[...] La intención del film "Dinámica de una gran ciudad" no es enseñar, ni moralizar, ni contar una historia: su efecto tiene que ser visual, puramente visual. Los elementos de lo visual en este film carecen de una absoluta conexión lógica con los otros; sus relaciones visuales, fotográficas, sin embargo, las enhebran en una asociación vital de eventos en el espacio y el tiempo y llevan al espectador activamente hacia el interior del dinamismo de la ciudad.

Conocemos al menos, eso sí, unas cuantas hojas del guión previo de esa $\mathrm{Di}$ námica de la gran ciudad, un guión muy atractivo por cuanto es visual, escrito y conceptual. En las primeras páginas del mismo aparece una interesante definición de lo que podía aportar el cine a esas traducciones modernas de la ciudad:

En la vida el hombre no puede percibir muchas cosas. A veces porque sus órganos no funcionan lo suficientemente rápidos, a veces porque los momentos de peligro, etc., le absorben con demasiada fuerza. En el tobogán casi todo el mundo cierra los ojos durante la gran caída. La cámara no. En general, apenas podemos observar objetivamente, por ejemplo, a niños pequeños, animales salvajes, puesto que durante la observación tenemos que considerar una serie de otras cosas. En la película es de otro modo. También una visión nueva.

La película habría comenzado con un plano de lo que Moholy llama Nacimiento de una construcción metálica, al que siguen imágenes (en picado y contrapicado) de grúas en movimiento mientras construyen una casa, y una vista 
de una fachada de ladrillos. Luego se suceden descripciones como las siguientes:

Primer plano. El movimiento continúa en un coche que pasa a toda velocidad hacia la izquierda. Se ve la misma casa frente al coche en el centro de la imagen (la casa retrocede siempre desde la derecha al centro; esto produce un movimiento rígido, como a golpes). Aparece otro coche. Este se mueve simultáneamente en dirección opuesta hacia la derecha - o - Fila de casas en un lado de la calle, transparente, pasa a toda velocidad por la derecha por la primera casa. Fila de casas desaparece hacia la derecha y vuelve a aparecer desde la derecha hacia la izquierda. Fila de casas unas frente a otras, transparente, pasando a toda velocidad en dirección opuesta, y en los coches cada vez más deprisa, hasta que pronto surge un CENTELLEO.

Abundan, además, las referencias a diversos espacios de la ciudad que nace a partir de sus elementos mecánicos, como puentes, viaductos, teleféricos, tren, raíles, ascensores de cristal, cabinas telefónicas de cristal, anuncios luminosos que repiten el apellido MOHOLY, antenas, torres, chimeneas, etc.

Esa descripción -bastante esperable en una película que iba a titularse $\mathrm{Di}$ námica de una gran ciudad- encuentra su inesperado contrapunto con un plano de un tigre, que da vueltas, furioso, dentro de su jaula. En otros momentos desfilarían otros elementos de desasosiego, como un lince, perros atados, de nuevo el tigre, espectáculos nocturnos de variedades, unas prostitutas, una autopsia en una morgue, un matadero, bueyes bramando, leones (en este caso Moholy indica explícitamente la función de estas "figuras del desasosiego": La frecuente e inesperada aparición de la cabeza del león pretende evocar malestar y agobio (otra vez - otra vez - otra vez). El público del teatro está de buen humor -iy la CABEZA vuelve OTRA VEZ! ), números de circo y finalmente un cadáver de pájaro que flota en el agua, como se apunta en el guión, muy lentamente.

Si la película se hubiera realizado finalmente, habría aparecido ya el que sería uno de los grandes leitmotivs de todas las visiones urbanas que firmaría Moholy Nagy: la presencia ominosa de la suciedad en las calles. La presentación de este motivo es indicada en el guión en los siguientes términos:

(La cámara es volcada rápidamente; se produce la sensación de una caída profunda) Bajo las calles principales, las cloacas. Brillo luminoso sobre el nivel del 
agua [...] Propulsor en el agua en profundidad. Entradas de cloacas debajo y sobre el nivel de agua. Por los canales con bote de motor hacia el depósito de basuras e inmundicias [...] Tratamiento de basuras en una fábrica. Montañas con tornillos oxidados, latas, zapatos, etc....

\section{A vueltas con la metrópoli y con las ciudades que no lo son.}

En 1926 sí consigue filmar su primera sinfonía urbana, Estilo de vida berlinés, muy en el tono de la que más tarde realizaría Walter Ruttmann y que es aceptada como la que suministra el esquema "canónico" para este tipo de producciones. En primer lugar, podemos destacar la (prevista) abundancia de planos picados y contrapicados que se recrean en el contraste entre ciertos monumentos urbanos y la presencia de viviendas de clase media, estandarizada y habitada por clases medias y bajas en su mayoría. Además, Moholy se concentra en mostrar la capital alemana como un escenario donde interactúan los seres humanos con el espacio construido: por ejemplo, unos niños jugando tranquilamente junto a una estatua de dimensiones colosales, de la que, de hecho, apenas vemos más que un fragmento de sus piernas, tan alto como los niños.

Aparece, en paralelo, el que se va a convertir en uno de los temas privilegiados en sus trabajos visuales sobre la ciudad: la presencia de la suciedad en las calles, a menudo en un más que intencionado contraste con la geometría de las losas que forman ese mismo suelo. Lo orgánico que se pudre desparramado sobre lo geométrico inalterable y, en cierto modo, impecable. Es como si mediante este argumento de confrontación visual, Moholy aspirara en el fondo a la síntesis entre figuración y abstracción, siendo incapaz de optar por una de ambas si eso supusiera la eliminación de la otra. De hecho, dicha propuesta de síntesis de opuestos es algo que en la URSS estaba realizando desde hacía unos años, por ejemplo, el constructivista Alexander Rodchenko, pero no era el único, ni mucho menos.

Por último, Moholy se detiene en diversas ocasiones en la idea -tan sugerente- del fragmento: vemos pies de señoras que parecerían carecer del resto del cuerpo, vemos trozos de bicicleta, de calle, andamios en un primer plano que los hace casi irreconocibles, etc. En este "triunfo de la poética del fragmento" subyace tanto un planteamiento muy típico del periodo de entreguerras (practicado, por ejemplo, por el grupo surrealista francés) como un claro 
convencimiento de tipo, diríamos, filosófico, en el sentido que la aceptación del fragmento supone la redacción de un discurso sobre la imposibilidad de alcanzar la totalidad del conocimiento de lo real. Y, en paralelo, la idea de que lo real tal vez no sea sino un conjunto desordenado de fragmentos.

Sin embargo, cuando llega 1928 -y quizás decidido a dar un cierto giro a su labor tras la marcha de la Bauhaus- realiza lo que para su mujer, Sybil, fue su primer filme documental ${ }^{3}$, Impresiones del Viejo Puerto de Marsella, aunque hoy pensamos que sigue siendo, sobre todo, un film experimental.

De hecho, el título debe aludir a cómo el artista recibió una primera impresión muy física de la ciudad francesa, hasta el punto de querer dejar constancia en una nota manuscrita, que reproduzco en su integridad:

Hace un calor tan terrible que cabría pensar que se podrían derretir las calles. $Y$ sin embargo las masas de gente siguen subiendo y bajando interminablemente por la ancha Cannebière. Suenan los tranvías, se apiñan los coches y entre ellos pasa lentamente una comitiva fúnebre hacia el viejo puerto. Seis mujeres llevan el ataúd, el coche fúnebre está decorado con flores artificiales especiales hechas de gasa y con reliquias sagradas, del tipo que se puede encontrar sólo en el campo, para honrar a la Virgen María y en los banquetes de Primera Comunión. Luchando y abriéndose camino a empujones por entre el tráfico, los deudos vestidos de negro avanzan en procesión bajo el abrasador calor del sol.

Abajo, en el puerto, todos los que no tienen ningún trabajo urgente que les mantenga ocupados o en movimiento están tumbados sobre una tabla de madera en el agua o en la orilla. Deslumbrados por la luz del sol, con los ojos cerrados, dejan pasar el mediodía dormitando. Cientos de barcos se mecen y allí, por encima de todos ellos, flota y resplandece el famoso Pont Transportateur. Infatigable, de acá para allá, de una orilla a la otra, sigue su camino y los foráneos lo admiran y lo valoran por su belleza. Este puente colgante es ciertamente una maravilla de la precisión técnica y de la elegancia. La estructura de acero de finas líneas que soporta sobre sus largas vigas el puente 'viajero' es una atracción notable, y es una delicia ver una y otra vez cómo el bajel repleto de gente,

${ }^{3}$ Moholy-Nagy, Sibyl (1963): Moholy-Nagy. Experiment in totality. MIT Press, Londres, Reino Unido, pág. 75. 
balanceándose y meciéndose ligeramente, inicia de nuevo su travesía por encima del agua del lado opuesto.

El calor del mediodía se hace tan intenso que, con la cabeza algo mareada, se tambalea uno hacia su casa, se sienta en la sombra de un café, y se pasa las horas más calurosas observando a la gente que pasa. De hecho, la gente de Marsella no es atractiva, apenas existe alguno que no parezca tener algún defecto moral o de otro tipo marcado en el rostro. No parece haber ninguno que no tenga una cicatriz alrededor de su oreja o de su ojo que dé fe de conflictos pasados. Es natural que un puerto de mar sea un lugar de encuentro de gente de todos los tipos y de todas las condiciones que, habiendo arruinado sus vidas en otras ciudades, intentan una vez más hacer fortuna aquí. Sin embargo, las chicas sí tienen un andar bonito y sus caderas son atractivas, y es quizás bajo el calor más tórrido cuando la ciudad revela sus rasgos más auténticos, pues la gente languidece demasiado como para mantener un autocontrol.

El film (de apenas 10 minutos de duración) es una mezcla extraña de experimentación en la multitud de planos picados que ofrece o en el minuto ( 3 '20" a $\left.4^{\prime} 20^{\prime \prime}\right)$ que dedica al puente transportador del que hablaba en su texto... y de repertorios argumentales que, de un modo u otro, dejaban ver la recepción de contenidos de crítica social y de recursos visuales procedentes del surrealismo. Por ejemplo, la sorprendente aparición de un carromato de gitanos (tema sobre el que volverá unos años después, como veremos), oso incluido; la presencia de escaparates, las aguas sucias del puerto y las calles, las montañas de basura, los edificios a punto de derrumbarse, la suciedad como seña de identidad de la ciudad. La última parte de la película se recrea en la lluvia, recibida como un alivio y casi un milagro en alguien que, como hemos podido leer, había quedado casi abatido por las duras jornadas de sol. Moholy-Nagy hablaba incluso, de un mareo o un aturdimiento, de un estado físico que propicia una nueva concepción de la realidad marsellesa. Los puntos de conexión -buscados explícitamente o no- de esas afirmaciones con las que los surrealistas aireaban por todo el mundo no deberían pasar desapercibidos, en mi opinión.

Que esta película no debe ser entendida a partir de ahora como una rareza en su producción lo confirma que por las fechas en que la estaba realizando preparó un proyecto junto a Ilya Ehrenburg que se iba a titular La rebelión de los pescadores, en el que el mundo del trabajo, la factoría, la huelga y la represión ocupaban un papel relevante. 
Aún quedaban dos interesantes películas. En 1930 aparece Juego lumínico: negro, blanco, gris, un puro espectáculo geométrico en la línea de lo que había enseñado pocos años atrás a sus alumnos de la Bauhaus y también, en estrecha relación con las primeras películas abstractas, como las de Oskar Fischinger o Viking Eggeling.

El ciclo concluirá en 1932 con otro film experimental donde se cuela -o, quizás, donde reclama su derecho a compartir escenario- lo documental. Se trata de Gitanos, sobre un pueblo que él conocía bien por su condición de húngaro. La película era un proyecto más que arriesgado por su rechazo de la creciente xenofobia que se vivía en Europa durante esos años. En realidad su título completo es Gitanos de la gran ciudad, y empieza, como le gustaba tanto, con un fragmento, en este caso de un carro, que deja paso al título.

Planos picados de un campamento gitano, donde lo primero que se narra es la higiene matinal, luego números de circo, mercado de caballos, gitanas que leen la mano, peleas de todo tipo (entre hombres, entre mujeres, entre niños), bailes, y sólo de forma muy tangencial, planos más abiertos del entorno urbano en el que están, si es que se puede llamar así, porque son arrabales sin más elementos que una calle asfaltada. Como había sucedido con Impresiones del Viejo Puerto de Marsella, la duración ronda los diez minutos, pero el tono es similar en cuanto a denuncia de los colectivos marginados en el proceso de desarrollo urbano.

Llegados a este punto ¿cómo organizar toda esa producción fílmica tan, en apariencia, dispar? Para uno de los mayores especialistas en la obra de Moholy-Nagy, sería clave su intención de proponer de nuevo una Gesamtwerk, una obra total donde los aspectos artísticos convivieran con los documentales y con los puramente experimentales:

al combinar imágenes fotográficas no artísticas que representan diversos aspectos de la vida (medios de transporte, deportes, baile, medicina, biología, astronomía, delincuencia, etcétera) con productos estéticos de la Nueva Visión (la publicidad, los fotogramas y las fotografías), Moholy-Nagy demostraba cómo el arte podía quedar completamente integrado en la vida ${ }^{4}$.

${ }^{4}$ A. I. Botar, Oliver: "La totalidad de la vida". Laszlo Moholy-Nagy. Valencia, IVAM, 1991, p. 163. Mucho más reciente es el catálogo de la exposición László Moholy-Nagy. El arte de la luz, Madrid, Cír- 
De hecho, en paralelo estaba pudiendo llevar a cabo esa estrategia globalizadora cuando fue encargado para comisariar la exposición Raum I dentro de la importantísima muestra Film und Foto, organizada en Stuttgart por la Deutscher Werkbund entre mayo y julio de 1929, y al año siguiente (de mayo a julio de 1930) cuando la Deutscher y el Grand Palais participaron en la muestra anual de la Société des Artistes Décorateurs de Paris.

\section{La caleidoscópica mirada de lo posmoderno: Muntadas.}

Antes de concluir, volvamos una última vez a Impresiones del Viejo Puerto de Marsella. Que es un film experimental, pese a aparentar ser documental, y que huye de la exclusividad de los tópicos de "malditismo" de la ciudad francesa (como reflejaría, sin ir más lejos, el film Marius de Alexander Korda en 1931) quedaría ratificado por una actuación artística muy posterior. En 1992 dos representantes de la Dirección de Asuntos Culturales de Marsella (Christine Breton y Bernard Gavoty) encargaron al artista multimedia Antoni Muntadas que diseñara un proyecto sobre la ciudad de Marsella. Fue presentado a los Ateliers d'Artistes de la ciudad mediterránea y se inscribía en una reflexión de ámbito superior titulada "Ville-musée", destinada precisamente a romper las barreras tradicionales entre ambos espacios y, al mismo tiempo, a convertir la ciudad francesa es un lugar de reflexión visual y artística sobre el hecho urbano.

En 1995 estaría listo ese trabajo, que Muntadas titula Marseille: mythes et stéréotypes. Regard des regards. Para conocer la naturaleza de ese producto resulta bastante aclaratorio conocer la descripción que hace el MNCARS en la ficha del mismo:

Montaje de textos, citas, eslóganes, entrevistas y fragmentos visuales tomados de diversas fuentes televisivas, publicitarias, musicales y, sobre todo, del cine propiciado por Marsella... con el propósito de mostrar una sucesión de mitos y estereotipos, reflexiones e interrogantes que constituyen un conjunto de puntos y contrapuntos de vista sobre esta ciudad francesa.

culo de Bellas Artes y La Fábrica, 2010, en el que destacaría el artículo de Jean-Paul Goergen, “Juego luminoso y reportaje social", págs. 197-216. 
¿A qué complejo producto visual nos enfrentamos? Se trata de dos maletas-contenedores, una con el proyector y con el film (en película de $35 \mathrm{~mm}$ ) y otra con la pantalla. Se podrían desplegar en cualquier barrio de la ciudad y proyectarían una grabación de casi una hora de duración en la que se intercalaban entrevistas a diversos especialistas en imagen y comunicación, así como una serie de fragmentos de películas francesas en las que Marsella era vista como lugar peligroso y violento. La sistemática y prolija enumeración de películas no incluye la obra pionera de Moholy-Nagy, lo que vendría a certificar la idea de que Impresiones del Viejo Puerto de Marsella es, sobre todo, un puro experimento visual fruto de la vanguardia. Ciudad moderna, siempre a medio hacer, tan necesaria como Nueva York, Berlín o París para explicar cómo se pensó el hecho urbano en el periodo de entreguerras.

Para Muntadas 5 , como decimos, ya no es relevante la sinfonía urbana de Moholy Nagy. Aunque, sin embargo, el trabajo comienza con una cita de Walter Benjamin que parece remitir claramente a esa misma visión de la ciudad como lugar sucio y casi animalizado, lo que nos hace pensar que, bajo la cita de Benjamin se esconde, camuflado, el recuerdo de la película de Moholy: Marsella, dentadura amarilla de lobo de mar el hocico abierto que deja escapar el agua salada entre sus dientes.

De inmediato, Muntadas despliega una extensa serie de casi veinte carteles que empiezan siempre con la palabra "Marsella" y que continúan con los siguientes adjetivos: ciudad de aventura, ciudad pintoresca, ciudad del viaje, vulgar y sucia, puerta de Oriente, de las pasiones contrarias, de contrastes, popular, naturaleza, mostrador, puerto, cosmopolita, de agua, abierta, de deportes, capital, Europuerto Sur, de congresos, de arte y puerta de Provenza.

Ese bombardeo de ideas asociadas a palabras permite reforzar la realidad laberíntica y casi indescifrable de la ciudad, que en gran medida será aumentada con la inclusión, en diversos momentos de la proyección, con otras citas como las de Joseph Roth, Marsella es Nueva York y Singapur, Hamburgo y Calcu-

\footnotetext{
${ }^{5}$ Una bibliografía sobre Muntadas y sus trabajos sobre la transformación de/en la ciudad debe incluir los siguientes trabajos: Intervenciones urbanas: proyectos y comunicaciones, San Sebastián, Diputación Foral de Guipúzcoa, 1995; City-guide: on traslation, Bremen, Neues Museum, 2004; Muntadas: espacios, lugares, situaciones, Santander, Fundación Marcelino Botín, 2008 y, por supuesto, la gran retrospectiva hasta el momento, Muntadas: entre-between, Madrid, MNCARS, 2011.
} 
ta, Alejandría y Port Arthur, San Francisco y Odessa; Tahar Ben Jelloun: Marsella es un enigma, una casa con varias puertas y ventanas siempre abiertas; o Blaise Cendrars: Marsella subsiste en el mismo lugar, insolente, feliz de vivir y más independiente que nunca.

Un largo recorrido en coche -en realidad, fragmentos de Recuerdos de Marsella (1980), film de René Allio- nos permite conectar la idea de viaje, duración en el tiempo y descripción de esa peculiar geografía urbana de Marsella, tan definida, como sabemos, por el violento contraste entre el mar, las montañas y un urbanismo brutal, donde las construcciones tradicionales (por lo demás, bastante convencionales y sin mayor interés) parecen sometidas a la rotunda verticalidad de bloques de pisos, en los que, por una parte, parece sobrevivir la huella de algunos dogmas del llamado "estilo internacional" (no en vano, como es bien sabido, allí sigue en pie la Unité d'Habitation (Cité Radieuse), de Le Corbusier, concluida en la inmediata segunda posguerra mundial, en concreto en el año 1945), y, por otra, el reconocimiento de que todos esos sueños, todas esas utopías, solo han sido capaces de producir engendros como los que se alzan en la ciudad.

Más de una treintena de títulos, de procedencia francesa en su abrumadora mayoría, sirven como fondo visual de una serie de entrevistas a profesionales de la imagen, el pensamiento y la ciudad. Por ser más exactos, estos son los títulos y directores, de ese gran mosaico de visiones (literarias o reales) que Muntadas elige para construir y deconstruir la ciudad mediterránea: L'affaire du grand hotel (André Hugon, 1945), L'argent fait le Bonheur (Robert Guédiguian, 1992), Borsalino (Jacques Deray, 1970), Cap canaille (Jean-Henri Roger, 1983), Fanny (Marcel Pagnol, 1932), Le grand frère (Francis Girod, 1982), Honoré de Marseille (Maurice Regamey, 1956), Justin de Marseille (Maurice Tourneur, 1934), Marche à l'ombre (Michel Blanc, 1984), Marius (Alexander Korda, 1931), Marseille contrat (Robert Parrish, 1974), Marseille son soleil (Paul Carpita, 1961), Mayrig (Henri Verneuil, 1961), Le port du désir (Edmond T. Grevile, 1954), Retour à Marseille (René Allio, 1980), La Scoumoune (José Giovanni, 1972), Tous peuvent me tuer (Henri Decoin, 1957), Transit (René Allio, 1991), Trois de la Cannebière (Maurice Canongue, 1955), Trois places pour le 26 (Jacques Demy, 1989), Un, deux, trois soleil (Bertrand Blier, 1992), Attentat à Marseille (INA, 1973), Carnet de route (Christine Ockent, 1990), L'heure exprise (René Allio, 1981), Jour de match (Bernard Zekri, 1994), Marseille de père en fils 
(Jean-Louis Conolli, 1989), Marseille Eurosport du Sud (Jacques Sorkine, 1972), Marseille ou la vieille ville indigne (René Allio, 1993), Marseille vu de Marseille (Soirée thématique d'ARTE, 1994), Rendez-vous avec le hasard (ARTE Strasbourg, 1993), Le temps de l'urbanisme (Philippe Brunet, 1962), I maschi (Gianna Nannini, 1987), Je danse le Mia (I AM, 1993).

No nos deberá extrañar, en consecuencia, que incluso en nuestros días se siga reflexionando sobre el futuro y la fisonomía de Marsella. Me estoy refiriendo, en concreto, al hecho de que, con motivo de haber sido nombrada Capital Europea de la Cultura 2013, se están llevando a cabo los trabajos para peatonalizar -precisamente- toda esa zona del Vieux Port, incluyendo una gigantesca marquesina que proteja del sol y que ha sido diseñada por el estudio de Norman Foster. Sin duda, me parece una metáfora de lo más oportuna para entender cómo una ciudad, y la ciudad en general, es capaz de seguir creando interés, no exento de polémica, entre todos aquéllos que se dedican a planificarla y, por supuesto, entre todos los que la dotan de pleno sentido viviendo dentro de ella. 